\section{CIEN AÑOS DE VITAMIN(A)S}

\author{
José M. ${ }^{a}$ Mato \\ CIC bioGUNE, Parque Tecnológico de Bizkaia, Derio, Bizkaia
}

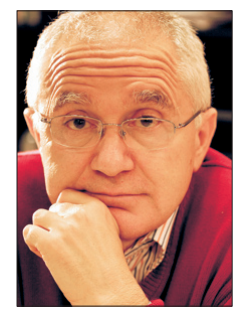

Deja que la comida sea tu medicina y la medicina, tu comida.

Hipócrates

En 1929, el premio Nobel de Medicina fue compartido por el holandés Christiaan Eijkman y el británico Frederick Hopkins. El primero fue galardonado por el descubrimiento del compuesto antineurítico vitamin y el segundo por el descubrimiento de las vitaminas que estimulan el crecimiento. El descubrimiento de las vitaminas, que ocupó el centro del escenario de la investigación bioquímica durante los años veinte y treinta, acabó con epidemias como el beri-beri (el origen de este término no está claro, una hipótesis es que proviene de una frase en senegalés que significa no puedo, no puedo, la otra es que deriva de una frase en árabe que significa asma de los navegantes) y la pelagra (que proviene del italiano pelle agra, piel rugosa). El beri-beri es una enfermedad neuromuscular, que antes del descubrimiento de las vitaminas mataba a decenas de miles de personas al año en las regiones tropicales y subtropicales del Este Asiático pero que también era frecuente en las Islas Molucas y en diversas áreas de Brasil; y la pelagra es una enfermedad crónica, con manifestaciones cutáneas y perturbaciones digestivas y nerviosas, descrita por primera vez en España en 1735 por Gaspar Casal, frecuente en regiones donde se consume una dieta basada en el maíz. El descubrimiento de las vitaminas también contribuyó de forma crítica a mejorar la salud de la población mundial en general.

¿Quién fue el descubridor de las vitaminas? La importancia de ciertos nutrientes en las dietas normales había sido propuesta por otros investigadores antes de los trabajos de Eijkman y Hopkins. Pero fue a comienzos del siglo XX cuando la existencia de las vitaminas, de nutrientes que se encuentran en ciertos alimentos y que es necesario ingerir en pequeñas cantidades para crecer adecuadamente o evitar diversas enfermedades, en su mayoría neurodegenerativas, se hizo súbitamente evidente. En 1912, Frederick Hopkins publicó un trabajo en la revista Journal of Physiology titulado Feeding experiments illustrating the importance of accessory food factors in normal dietaries que es considerado por muchos como el primer trabajo donde la existencia de las vitaminas quedó sólidamente establecida. Hopkins observó que las ratas alimentadas con una dieta conteniendo carbohidratos, proteínas, grasas y sales minerales dejaban de crecer si no se suplementaba dicha dieta con pequeñas cantidades de leche, lo que acertadamente le llevó a concluir que la leche contenía trazas de sustancias que eran necesarias para el crecimiento. Asimismo, estos estudios le llevaron a formular la hipótesis de que ciertas enfermedades, como el raquitismo y el escorbuto, estaban causadas por deficiencias en estas sustancias esenciales y que ahora conocemos como vitamina A (ácido ascórbico) y D (calciferol). Sin embargo, parece que Frederick Hopkins no estaba totalmente convencido de haber sido el descubridor de las vitaminas y en su conferencia Nobel le dedica más tiempo a justificar la primicia de su descubrimiento que a explicar su trabajo de investigación. En cualquier caso, Frederick Hopkins fue un gran científico y se merecía el premio Nobel por sus trabajos pioneros sobre el metabolismo del ácido úrico y del ácido láctico. Hopkins aisló el aminoácido triptófano, un componente necesario en la nutrición, y desarrolló el concepto de aminoácidos esenciales, es decir aquellos que un organismo no puede sintetizar por si mismo. También aisló el glutatión, un tripéptido con un enlace peptídico inusual entre el grupo amino de la cisteína y el grupo carboxilo de la cadena lateral del glutamato, y uno de los antioxidantes celulares más abundantes (su concentración intracelular es aproximadamente $5 \mathrm{~mm}$ ) que ayuda a las células a protegerse de los radicales libres y los peróxidos. Fue el primer catedrático de Bioquímica de la Universidad de Cambridge, una especialidad que hasta entonces recibía el nombre de fisiología química y que andaba bastante 
alicaída, y fundador de una dinastía de bioquímicos británicos que ha dominado de forma brillante esta especialidad durante gran parte del siglo XX.

El término vitamina fue acuñado hace 100 años por el bioquímico polaco Kazimierz Funk para denominar a las sustancias vitales presentes en los alimentos. Mientras trabajaba en el Instituto Lister de Medicina Preventiva de Londres sobre diversas enfermedades producidas por carencias alimenticias como el escorbuto, el beri-beri o la pelagra, Funk identificó, mediante estudios con palomas, que la naturaleza del componente del arroz y otros alimentos que prevenía el beri-beri, y que había sido descubierta a finales del siglo XIX por Christiaan Eijkman, era una amina. A esta sustancia le dio el nombre de vitamine, término que proviene de vital amine (amina vital) en la creencia, años después demostrada errónea, de que todas las sustancias vitales eran aminas. La vitamine fue identificada en 1936 por Robert Williams como la tiamina y en la actualidad se conoce como vitamina $B_{1}$. Kazimierz Funk demostró que tan sólo 1 miligramo de esta vitamine que había purificado era suficiente para prevenir el beri-beri. La e al final de la palabra vitamine fue eliminada más tarde al descubrirse que no todas las vitaminas eran aminas. En castellano, sin embargo, no se hizo esta modificación y se sigue diciendo vitaminas en lugar de vitamins como hubiese sido más correcto según el criterio internacional. Kazimierz Funk también aisló el ácido nicotínico, conocido como niacina o vitamina $B_{3}$, que posteriormente se demostró servía para curar la pelagra. En 1913 publicó un libro que aún puede conseguirse, Die Vitamine. En mi opinión, Funk se merecía haber compartido el premio Nobel junto a Eijkman y Hopkins.

Con anterioridad a los estudios de Hopkins y Funk, Christiaan Eijkman había descubierto que la causa del beri-beri era la deficiencia en una substancia vital en la nutrición de los nativos de Java que se encuentra en la cáscara del arroz. Y en 1897 descubrió que el arroz descascarillado producía en los pollos una enfermedad parecida al beri-beri y que sanaban cuando se les suministraba arroz natural. Por estos elegantes experimentos de nutrición Christiaan Eijkman fue galardonado con el premio Nobel de Medicina.

Aunque la investigación sobre las vitaminas vivió sus mejores momentos hace ya muchas décadas, aún se desconocen los mecanismos por los que la deficiencia en ciertas vita- minas causan enfermedades como el beri-beri, la pelagra, el escorbuto, producen enfermedades neurodegenerativas o retrasan el crecimiento. Así, por ejemplo, la deficiencia materna en ácido fólico (vitamina $B_{9}$ ) impide que se cierre el tubo neural durante el desarrollo fetal en el embarazo causando espina bífida, pero se desconoce como lo hace. El suplemento con ácido fólico en las mujeres en edad fértil previene hasta el $60-70 \%$ de los casos de espina bífida. Debido a esta relación entre el ácido fólico y la espina bífida, en 1998 los Estados Unidos, Canadá y Chile comenzaron a suplementar el grano de los cereales con ácido fólico. En la actualidad son muchos los países que suplementan la dieta (cereales, harinas, harina de maíz, pastas, arroz, y otros productos) con ácido fólico. Es la primera vez en la historia que para proteger a unos pocos de desarrollar una enfermedad (la espina bífida es una enfermedad rara que afecta a alrededor de uno de cada 1.000 nacidos) se lleva a cabo una intervención alimentaria que tiene como objetivo aumentar la concentración de ácido fólico en la población general. El suplemento con ácido fólico ha reducido drásticamente el número de casos de espina bífida en estos países pero, como no se conoce exactamente como actúa, es imposible asegurar que al elevar los niveles de esta vitamina de manera indiscriminada no se esté aumentando el riesgo de la población general, o de algún grupo específico dentro de la población general, de desarrollar algún otro tipo de enfermedades.

Este argumento está justificado ya que el ácido fólico puede enmascarar la deficiencia en cianocobalamina o vitamina $B_{12}$. El suplemento con ácido fólico corrige la anemia asociada a la deficiencia de vitamina $B_{12}$ (anemia perniciosa), pero no corrige los efectos neurológicos causados por dicha deficiencia. El ácido fólico es también necesario para la síntesis del nucleósido timidina, imprescindible para la síntesis de DNA y por consiguiente para la división celular. Las células cancerígenas se dividen rápidamente para lo cual necesitan transportar ácido fólico ávidamente a su interior, por lo que se ha sugerido que el exceso de ácido fólico puede promover la progresión del cáncer. Esta hipótesis se fundamenta en los elegantes experimentos realizados por el estadounidense Sidney Farber en los años 40 en el Hospital Infantil de Boston. Farber descubrió que la administración de ácido fólico empeoraba el pronóstico de las leucemias y que una dieta deficiente en ácido fólico las mejoraba. En 1947, un grupo de investigadores liderados por Farber demostró que la aminopterina, un 
análogo del ácido fólico desarrollado por Yellapragada Subbarao Ledle, inducía la remisión del cáncer en niños con leucemia linfoblástica aguda marcando el comienzo de la quimioterapia en oncología. En los años 50 se sintetizó un nuevo análogo del ácido fólico, el metotrexato, con mejores propiedades curativas y menor toxicidad. El metotrexato inhibe la dehidrofolatoreductasa, una enzima que cataliza la síntesis del tetrahidrofolato, precursor de la forma biológicamente activa del ácido fólico necesaria para la sintesis de timidina $y$, por consiguiente, de DNA, RNA y proteínas.. El metotrexato sigue utilizándose en la actualidad no sólo para tratar diversas formas de cáncer sino para el tratamiento de otras enfermedades como la artritis reumatoide o la enfermedad de Crohn.

Asimismo, el ácido fólico puede incrementar la concentración de S-adenosilmetionina (SAMe), una molécula derivada del aminoácido esencial metionina cuya principal función es servir de intermediario para donar el grupo metilo de este aminoácido a múltiples aceptores, incluidos el DNA y numerosas proteínas. La metilación del DNA, un proceso que se conoce con el nombre general de epigenética, es uno de los mecanismos que usan las células para inactivar o silenciar genes específicos. Entre los genes susceptibles de ser silenciados mediante metilación hay un grupo que se conoce con el nombre general de genes supresores de tumores. Es importante recordar que durante el inicio y progresión del cáncer estos genes supresores de tumores se encuentran frecuentemente silenciados mediante metilación. Un grupo importante de proteínas que son también susceptibles de ser metiladas por la SAMe son las histonas. Las histonas son el principal componente proteico de la cromatina y sirven de matriz para empaquetar el DNA en unas estructuras denominadas nucleosomas. Las histonas, que son extremadamente básicas (cerca del 20\% de sus aminoácidos son lisina y arginina), se unen a los grupos fosfato del DNA cargados negativamente. Además de este papel estructural, las histonas tienen un papel fundamental en la regulación de la expresión génica. Como norma general, la metilación de histonas inhibe la transcripción de los genes a los que se encuentran asociadas. Como ocurre en el caso del DNA, la expresión de numerosos genes que desempeñan un papel fundamental durante la proliferación, diferenciación y muerte celular están regulados por la metilación de histonas. De manera que no es posible asegurar que el suplemento de la población general con ácido fólico no esté modificando la concentración de SAMe en uno u otro tejido e incrementando en ciertos individuos el riesgo de desarrollar cáncer, como por ejemplo el cáncer de colon, o alguna de las enfermedades asociadas al envejecimiento, como las enfermedades neurodegenerativas, debido a la metilación y silenciamiento de ciertos genes específicos o de las histonas asociadas a estos genes.

La solución, por consiguiente, está en administrar ácido fólico sólo a aquellas personas que lo necesiten, de manera que los beneficios de este tratamiento superen a los riesgos. El tubo neural se cierra entre la tercera y cuarta semanas de gestación, de modo que la administración de ácido fólico al inicio del embarazo no es una opción válida pues para cuando se consigue elevar la concentración de ácido fólico en el feto es ya demasiado tarde. Esta es la justificación para suplementar con ácido fólico a todas las mujeres en edad fértil, aunque sería deseable poder hacerlo sólo en aquellas que de verdad lo necesiten, es decir cuando haya evidencia de la existencia de deficiencia en ácido fólico o su metabolismo. La deficiencia de ácido fólico, en ciertos casos, puede inhibir la síntesis de DNA en las células normales, que también se dividen aunque en general lo hacen más lentamente que las células tumorales, lo cual puede promover la aparición de errores en la secuencia del DNA y la iniciación del cáncer, estando también justificado en estos casos la suplementación con ácido fólico. Se trata en definitiva, de conseguir personalizar la medicina para mejorar la efectividad de los tratamientos maximizando los beneficios y reduciendo los riesgos.

La suplementación con ácido fólico tuvo también como objetivo reducir los niveles de homocisteína en sangre de la población general. La homocisteína es un aminoácido no proteico producto del metabolismo de la SAMe y cuyo catabolismo depende, entre otros factores, de la concentración de ácido fólico. Los estudios epidemiológicos habian relacionado previamente el aumento en la concentración de homocisteína en sangre con el riesgo de padecer enfermedad cardiovascular. Así que el argumento de los epidemiólogos fue, que la suplementación con ácido fólico disminuiría el riesgo de padecer enfermedad cardiovascular en la población general. Sin embargo, los resultados de los estudios de suplementación con ácido fólico no han confirmado esta hipótesis, llamando una vez más la atención sobre el riesgo de estas intervenciones nutricionales sobre la población general. Es importante hacer notar que estos resultados negativos no deben lle- 
varnos a la falsa conclusión de que el tratamiento con ácido fólico no pueda ser beneficioso para reducir el riesgo de desarrollar enfermedad cardiovascular en un grupo específico de personas. La relación entre el ácido fólico, el metabolismo de la homocisteina y el riesgo de enfermedad cardiovascular es un área importante de investigación que merece ser apoyado.

La suplementación no obligatoria de los alimentos con nutrientes esenciales se ha convertido en una práctica habitual en los países desarrollados, siendo numerosos los productos, lácteos, harinas y cereales, que están suplementados con vitaminas. El primer alimento que se suplementó con vitaminas fue la margarina, y se hizo en los años 40 en el Reino Unido durante la segunda Guerra Mundial. Se suplementó con vitamina $A$ y $D$ debido a que el contenido de estas vitaminas en la margarina es inferior al de la mantequilla. La margarina aún sigue suplementándose con vitamina D por ley en el Reino Unido. No existe una norma común a este respecto en la Unión Europea. Además de alimentos suplementados con vitaminas $A$ o $D$, también los hay que están suplementados con vitaminas $E$ (tocoferol), $B_{2}$ (riboflavina), $B_{6}$ (piridoxina) o $B_{12}$. Un gran número de niños, adolescentes y adultos en los países desarrollados toman diariamente pastillas que contienen múltiples vitaminas, nutrientes esenciales, como la colina y la betaína, y diversos minerales, como el hierro y el zinc convencidos de que es bueno para su salud. Sin embargo, no hay estudios clínicos realizados de manera controlada que avalen la hipótesis de que estos suplementos son beneficiosos para la salud de una población sobrealimentada en donde más del 30\% de los individuos tienen sobrepeso y la hipertensión, la diabetes tipo 2, y la enfermedad pulmonar obstructiva crónica son muy frecuentes. Linus Pauling, uno de los químicos más brillantes del siglo $X X$, que recibió el premio Nobel de Química en 1954 y el premio Nobel de la Paz en 1962, fue uno de los pioneros en introducir, a comienzos de los años 70, el concepto de la utilización de elevadas concentraciones de vitamina $\mathrm{C}$ para prevenir los resfriados y en el tratamiento del cáncer. Estudios realizados de manera controlada años más tarde no confirmaron esta hipótesis de Pauling sobre el efecto beneficioso de la vitamina $C$ en el tratamiento del cáncer.

Los antioxidantes son también ampliamente utilizados como suplementos nutricionales. Entre ellos, los más frecuentemente empleados son las vitaminas A, C y E (toco- ferol), los polifenoles (como el resveratrol) y los flavonoides. Estas moléculas surgieron hace unos 100 millones de años durante la adaptación de las plantas marinas a la vida terrestre para defenderse de las sustancias reactivas del oxígeno, como los radicales libres hidroxilo, que se generan durante la fotosintesis. La fotosintesis consiste en la reducción del $\mathrm{CO}_{2}$ para la formación de hidratos de carbono y la oxidación del agua para formar oxígeno y ATP, un proceso en el que también se producen sustancias reactivas del oxígeno que son eliminadas por una compleja red de moléculas como las vitaminas $A, C$ y $E$, y enzimas antioxidantes. En las células animales, durante la fosforilación oxidativa, también se generan sustancias reactivas de oxígeno. La fosforilación oxidativa consiste en la oxidación de los nutrientes, principalmente carbohidratos, lípidos y aminoácidos, para la formación de ATP y la reducción del oxígeno para formar agua. Durante la reducción del oxígeno en la mitocondria se forman radicales libres que dañan diversos componentes celulares, como las proteínas, DNA y lípidos, contribuyendo posiblemente a la aparición de diversas enfermedades, como la aterosclerosis, el cáncer y el envejecimiento. Para contrarrestar la acción de estos radicales libres y limitar el daño que producen, las células contienen numerosos antioxidantes como las vitaminas $C y$

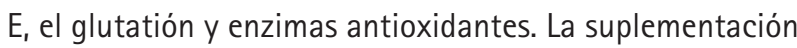
con vitaminas y otras moléculas antioxidantes persigue reducir la acción tóxica de estas sustancias reactivas del oxígeno. No existen, sin embargo, estudios realizados de manera controlada que avalen la hipótesis de que la suplementación de la población general con estos nutrientes previene el cáncer, la enfermedad cardiovascular o retrase el envejecimiento. $Y$ en cualquier caso, el objetivo debe ser suplementar con antioxidantes sólo a aquellas personas que lo necesiten, es decir a aquellas que tengan un aumento del daño oxidativo.

Una alternativa a la suplementación con antioxidantes para reducir el daño producido por la generación de radicales libres es disminuir la generación de estas sustancias. Una forma de hacerlo es mediante la restricción calórica. La restricción calórica consiste en seguir un régimen dietético que restringe las calorias totales ingeridas. Cuando no está asociada con malnutrición, la restricción calórica mejora la salud general y aumenta la longevidad en numerosas especies animales incluidos los roedores. Aunque el efecto de la restricción calórica sobre la salud y longevidad en humanos es un tema de debate, estos estudios son im- 
portantes porque pueden proporcionar información sobre como reducir la generación mitocondrial de radicales libres sin los efectos secundarios que produce la pérdida excesiva de peso. Por ejemplo, estudios realizados en Drosophila han demostrado que una dieta deficiente en metionina aumenta la longevidad de estas moscas sin reducir la fertilidad, uno de los efectos secundarios de la pérdida excesiva de peso. En roedores, la restricción de la metionina de la dieta aumenta la longevidad, mientras que la deficiencia severa de este aminoácido produce hígado graso (esteatosis) que progresa a esteatohepatitis (esteatosis con fibrosis, inflamación y fibrosis), desnutrición y cáncer de hígado. Es decir, la metionina actúa como una señal, posiblemente a través de la SAMe, y tanto el exceso como el defecto de esta molécula tienen efectos nocivos sobe la salud. Comprender como una dieta restringida en metionina mejora la salud general o incrementa la longevidad puede llevar a la identificación de dianas terapéuticas sobre las que actuar para conseguir los efectos beneficiosos de esta dieta minimizando sus efectos secundarios.

Es bien conocido que las células tumorales, con independencia del oxígeno disponible, producen la mayoría del ATP vía glicólisis y no mediante fosforilación oxidativa. Este fenómeno se conoce con el nombre de efecto Warburg, en honor de Otto Warburg, el gran bioquímico alemán y premio Nobel de Medicina (1931) que lo descubrió. Este cambio en el metabolismo permite a las células cancerosas optimizar la utilización de los átomos de carbono de la glucosa y de otros nutrientes para sintetizar las proteínas, lípidos y ácidos nucleicos necesarios para mantener el crecimiento celular acelerado que las caracteriza reduciendo, al mismo tiempo, la generación de radicales libres y sus efectos dañinos sobre proteínas, DNA y lípidos. Aprender como las células cancerosas reprograman su metabolismo no sólo puede llevar a la identificación de nuevas terapias contra el cáncer, sino a la identificación de dianas que permitan manipular el metabolismo para mejorar las salud.

Otros nutrientes esenciales que han recibido gran atención durante los últimos años son los ácidos grasos $n-3$. El término $n-3$, también Ilamado omega-3 o $\omega-3$, significa que el primer doble enlace se encuentra entre el tercer y cuarto átomo de carbono contando desde el grupo metilo, siendo $n$ el número total de átomos de carbono de la cadena de ácido graso. Los ácidos grasos $\omega$-3 más importantes en la nutrición humana son: el ácido $\alpha$-linolénico (18:3, $n-3$; ALA), el ácido eicosapentaenoico (20:5, n-3; EPA) y el ácido docosahexaenoico $(22: 6, n-3 ;$ EPA). Aunque se ha propuesto que la suplementación con ácidos grasos $\omega-3$ puede ser eficaz en el tratamiento de diversas patologías, como la diabetes tipo 2, enfermedad de Crohn, colitis ulcerosa, enfermedades cardiovasculares, etc. en general las pruebas son insuficientes, siendo necesarios más ensayos clínicos que confirmen estas indicaciones. Una vez más, no hay razón científica que justifique la suplementación de la población general con ácidos grasos $\omega-3$.

En resumen, no existe evidencia científica que justifique la suplementación de la dieta con vitaminas y otros nutrientes esenciales para mejorar la salud o aumentar la longevidad de la población general. Sin embargo, la utilización de alguno de estos nutrientes como medicamentos (es decir, bajo control médico) está justificada en diversas situaciones, como por ejemplo: la suplementación con ácido fólico de la mujeres deficientes en esta vitamina para prevenir la espina bífida; la suplementación con SAMe para mejorar la supervivencia en pacientes con cirrosis hepática; y la suplementación con vitamina E para el tratamiento de la esteatohepatitis, una enfermedad que afecta hasta al 10\% de la población en los países desarrollados.

Cien años después de que Kazimierz Funk acuñara el término vitamina y de demostrarse la existencia de nutrientes esenciales, la investigación sobre el papel del metabolismo, y por consiguiente de las vitaminas y nutrientes esenciales que lo regulan, en procesos como la diabetes, obesidad, enfermedad del hígado graso, enfermedades neurodegenerativas y cáncer, ha recobrado un gran interés. Así, en la última década se ha observado que mutaciones en diversos genes causantes de cáncer afectan al metabolismo y que estos cambios metabólicos desempeñan un papel fundamental en el inicio y progresión del cáncer. Estos resultados abren la posibilidad de desarrollar nuevas terapias contra el cáncer actuando sobre rutas metabólicas concretas. Por ejemplo, en el cáncer de hígado el principal gen responsable de la síntesis de SAMe se encuentra inactivado y su reactivación inhibe el crecimiento de las células tumorales. 